\title{
Optimal Switching Pattern for PWM AC-AC Converters Using Bee Colony Optimization
}

\author{
Wanchai Khamsen ${ }^{\dagger}$, Apinan Aurasopon*, and Chanwit Boonchuay ${ }^{* *}$ \\ ${ }^{\dagger}$ Faculty of Engineering, Rajamangala University of Technology Lanna, Lampang, Thailand \\ Faculty of Engineering, Mahasarakham University, Maha Sarakham, Thailand \\ ${ }^{* *}$ Faculty of Industrial and Technology, Rajamangala University of Technology Rattanakosin, Prachuap Khiri Khan, \\ Thailand
}

\begin{abstract}
This paper proposes a harmonic reduction approach for a pulse width modulation (PWM) AC-AC converters using Bee Colony Optimization (BCO). The optimal switching angles are provided by BCO to minimize harmonic distortions. The sequences of the PWM switching angles are considered as a technical constraint. In this paper, simulation results from various optimization techniques including BCO, Genetic Algorithm (GA), and Particle Swarm Optimization (PSO) are compared. The test results indicate that $\mathrm{BCO}$ can provide a better solution than the others in terms of power quality and power factor improvement. Lastly, experiments on a $200 \mathrm{~W}$ AC-AC converter confirm the performance of the proposed switching pattern in reducing harmonic distortions of the output waveform.
\end{abstract}

Key words: Bee colony optimisation, Converter, Harmonic reduction, PWM AC chopper

\section{INTRODUCTION}

In modern applications of power electronics, voltage adaptability of the energy supply is increasingly required. The AC-AC converter has become a major component in various types of control equipment such as heating, lighting and motor speed controllers. Energy efficiency improvement techniques also need soft start control and power factor correction regulated by the variable voltage converters replacing regular fixed AC sources [1]. In general, phase angle control is used for voltage adaptation. In addition, average output voltage can be controlled by varying the thyristor firing angle [2]. The phase angle control approach has many advantages. For example, it can be conveniently implemented and exhibits cost effectiveness for large scale applications. However, the delay of the firing angle causes discontinuation of the power flow and significant harmonics to both the input and output sides.

\footnotetext{
Manuscript received Sep. 8, 2013; accepted Dec. 12, 2013

Recommended for publication by Associate Editor Yong Kang.

${ }^{\dagger}$ Corresponding Author: wanchai kh@rmutl.ac.th

Tel: +66-5434-2547, Rajamangala Univ. of Tech. Lanna

*Faculty of Engineering, Mahasarakham University, Thailand

**Faculty of Industrial and Technology, Rajamangala University of

Technology Rattanakosin, Thailand
}

For an alternative solution, a PWM AC chopper is suggested for an $\mathrm{AC}$ voltage controller. Using the chopping technique, the $\mathrm{AC}$ voltage signal is modified as a PWM signal to regulate the output voltage. This approach can provide nearly sinusoidal current and voltage waveforms. In addition, it can improve both power factor and power quality. Since the switching frequency is limited by the switching losses in high power and high voltage applications, harmonic filter techniques are required to eliminate the low harmonic components caused by low frequency choppers.

The harmonic elimination methods used in AC choppers are similar to those employed in PWM inverters [3]-[8]. The general technique is that the waveform is analyzed in the frequency domain using Fourier approaches. In addition, the Newton-Raphson technique is adopted to solve non-linear equations with the iterative computation. Recently, stochastic search techniques have been widely applied to solve complex and non-convex optimization problems. For related applications, the switching angles of the PWM pattern are obtained by various heuristic approaches including genetic algorithm (GA), particle swarm optimization (PSO), and artificial neural network (ANN) [9]-[19]. All of the mentioned techniques aim to minimize the total harmonic distortion (THD) of the converter and to provide an optimal solution.

A branch of nature inspired algorithms known as swarm 
intelligence is focused on insect behavior such as Ant Colony Optimization (ACO). Recently, Bee Colony Optimization (BCO) was proposed by Karaboga in 2005 [20]. The BCO algorithm is a very simple and robust stochastic optimization algorithm when compared with previous algorithms. In addition, it is a novel and attractive approach for application in the power electronic area.

In this paper, an optimal switching strategy based on BCO for PWM AC-AC converters is proposed. BCO is adopted to provide the optimal switching angles of the PWM pattern. The proposed approach aims to minimize the harmonic distortion of converter's output waveforms with satisfying technical constraints of the switching angle sequences. Results from previous works are compared in this paper. In addition, an experiment with a $200 \mathrm{~W}$ AC-AC converter is used to confirm the performance of the proposed switching pattern in terms of reducing the harmonic distortions of the output waveform.

This paper is organized as follows. Section II describes the background of PWM AC-AC converters and presents the BCO concept. Section III expresses the problem formulation of the optimal switching strategy. Section IV proposes the BCO algorithm to provide the optimal PWM switching patterns. Sections V and VI shows the simulation and experimental results, respectively. And the last section concludes the paper.

\section{BACKGROUND}

\section{A. PWM AC-AC Converters}

The power circuit configuration of a PWM AC-AC converter is shown in Figure 1(a). Switch $S_{1}$ controls the power delivered to the load and switch $S_{2}$ is the freewheeling path to transfer energy to the load when switch $S_{I}$ is turned off.

In a conventional PWM AC chopper, the switching pattern is regularly fixed. This conveys the low order harmonics to the input and output waveforms. A harmonic elimination technique is an adaptation of the switching angles to reduce the waveform distortion. In Figure 1(b), improved input and output waveforms are shown. Using this technique, the total harmonic distortion is also reduced. In this paper, the optimal switching angles for the PWM AC-AC converter are provided by stochastic search approaches.

In the PWM chopper approach, the output voltage is controlled by the switching pattern. Thus, $M$ pulses are required for a quarter of a sinusoidal cycle. In addition, switch $S_{l}$ is turned on at different switching angles $\alpha_{l}$, $\alpha_{2}, \ldots \alpha_{M}$ and turned off at angles $\beta_{l}, \beta_{2}, \ldots \beta_{M}$. Using the Fourier series expression, the output voltage can be written as:

$$
v_{o}(\omega t)=\sqrt{2} V_{i}\left(a_{0}+\sum_{n=1}^{\infty}\left(A_{n} \sin (n \omega t)+B_{n} \cos (n \omega t)\right)\right)
$$

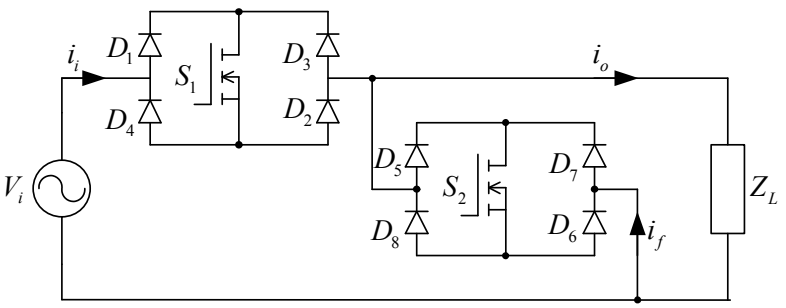

(a)

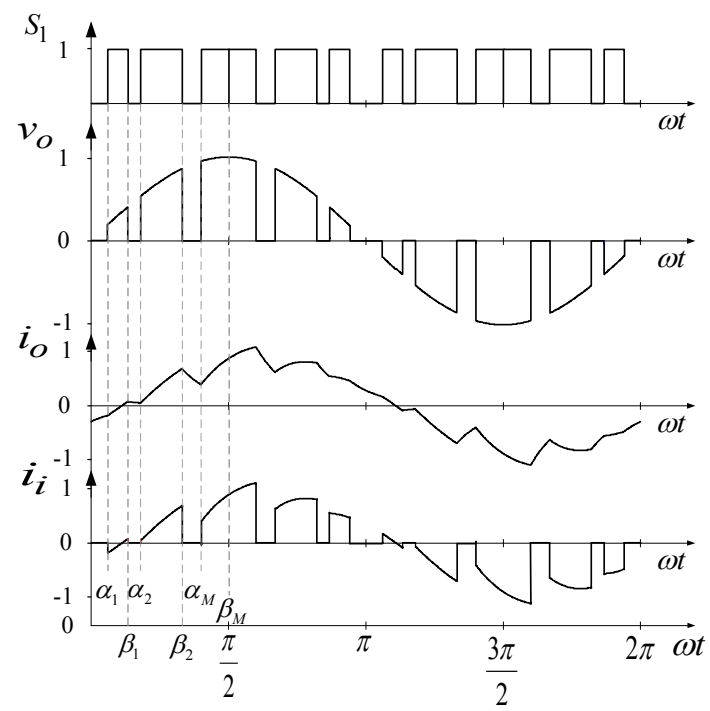

(b)

Fig. 1. PWM AC chopper. (a) Power circuit configuration. (b) PWM pattern, waveforms of output voltage/current and input current.

Where $n=1,2,3 \ldots$

By considering only the odd components of the waveform in (1), the output voltage can be written as:

$$
v_{o}(\omega t)=\sqrt{2} V_{i} \sum_{n=1}^{\infty} A_{n} \sin (n \omega t)
$$

Where $n=1,3,5 \ldots$

The fundamental coefficient $A_{1}$ is expressed as:

$$
A_{1}=\frac{1}{\pi} \sum_{k=1}^{M}\left[\left(\beta_{k}-\alpha_{k}\right)-\frac{\sin 2 \beta_{k}-\cos 2 \alpha_{k}}{2}\right]
$$

The harmonic coefficient $A_{n}$ is expressed as:

$$
\begin{array}{r}
A_{n}=\frac{1}{\pi} \sum_{k=1}^{M}\left[\frac{\sin \left((n-1) \beta_{k}\right)-\sin \left((n-1) \alpha_{k}\right)}{(n-1)}\right. \\
\left.-\frac{\sin \left((n+1) \beta_{k}\right)-\sin \left((n+1) \alpha_{k}\right)}{(n+1)}\right] .
\end{array}
$$


Where switch $S_{1}$ is turned on at various switching angles $\alpha_{1}, \alpha_{2}, \ldots \alpha_{M}$ and turned off at $\beta_{1}, \beta_{2}, \ldots \beta_{M}$, where $M$ is the pulse per quarter cycle.

The total harmonic distortion of the load current and voltage are defined as:

$$
\begin{gathered}
T H D_{i}=\frac{\sqrt{\sum_{n=3}^{\infty} I_{o n}{ }^{2}}}{I_{o 1}}, \\
T H D_{v}=\frac{\sqrt{\sum_{n=3}^{\infty} V_{o n}^{2}}}{V_{o 1}} .
\end{gathered}
$$

Where $n=3,5,7 \ldots$

\section{B. Bee Colony Optimization}

Bee Colony Optimization (BCO) mimics the intelligent behaviors of honey bees and it was proposed by Karaboga in 2005 [20]. The BCO algorithm has an advantage in providing global optimal solutions. In addition, it has the capability of solving difficult combinatorial optimization problems.

A colony of bees for the collection and processing of nectar consists of two groups: scout bees and worker bees. The scout bees are responsible for searching for sources of nectar, while the worker bees are responsible for loading the nectar to the hive. The processes of the intelligent behaviors of scout bees can be summarized as follows:

- Scout bees seek the sources of nectar in different directions and return to the hive.

- After that, the scout bees dance to inform the quality, quantity, direction and distance of the food supply.

- Then, the colony of bees decides to send worker bees to bring nectar to the hive.

This bee behavior is converted to a heuristic search algorithm including the steps of initialization, search, evaluation and update. The BCO algorithm applied to the optimal switching problem is described in Section IV.

\section{PROBLEM FormULATION}

Here, the optimal switching pattern problem for PWM AC-AC converters is formulated as an optimization problem. The objective of the function is to minimize the THD expressed as:

$$
\operatorname{Min}_{\alpha, \beta} F=\left[\left(A_{1}-V_{o, r e f}\right)^{2}+A_{3}^{2}+A_{5}^{2}+\ldots+A_{n}^{2}\right]^{\frac{1}{2}}
$$

Subject to:

$$
0 \leq \alpha_{1} \leq \beta_{1} \leq \alpha_{2} \leq \beta_{2} \leq \ldots \leq \alpha_{M} \leq \beta_{M}
$$

Where $A_{1}$ is the fundamental coefficient of the output voltage, $V_{o, \text { ref }}$ is the reference output voltage, $\beta_{M}$ is equal to $\pi / 2$, and $M$ is number of pulse per quarter cycle of the PWM waveform. The boundary of each switching angle can be determined with a simple calculation. For example, at $M=3$, the fixed interval $\phi$ is equal to $\pi / 6$. Thus, the boundaries of the switching angles are as follows:

$$
0 \leq \alpha_{1} \leq \beta_{1} \leq \frac{\pi}{6}, \frac{\pi}{6} \leq \alpha_{2} \leq \beta_{2} \leq \frac{\pi}{3}, \frac{\pi}{3} \leq \alpha_{3} \leq \beta_{3}=\frac{\pi}{2}
$$

The optimization model described in equations (7) and (8) is used to design a converter to reduce harmonic distortions. It requires an efficient optimizer to solve the problem as formulated. In the next section, a solution algorithm based on BCO is described.

\section{Proposed SOLUTION AlgorithM}

In this section, the $\mathrm{BCO}$ algorithm to provide optimal PWM patterns is shown in Figure 2 and described as follows:

Step 1: Specify the BCO parameter as shown in table 1 and the AC voltage controller such as $M$ and $V_{o}$.

Step 2: Randomly generate the initial populations $(N)$ of the switching angles, $\alpha$ and $\beta$, while satisfying the constraints using the following equations:

$$
\begin{gathered}
\alpha_{i}=(\phi \cdot(i-1))+(\operatorname{rand}(0,1) \cdot \phi) \\
\beta_{i}=\alpha_{i}+\left(\operatorname{rand}(0,1) \cdot\left((\phi \cdot i-1)-\alpha_{i}\right)\right)
\end{gathered}
$$

Where $i=1$ to $M$.

Step 3: Evaluate the fitness value of the initial population and arrange the fitness in descending order using the fitness function as:

$$
\text { Fitness }=1-F
$$

Where $F$ is described in (7). For dealing with the constraint, the violated angle is adjusted to the nearest boundary.

Step 4: Select $S$ best solutions for the neighborhood search.

Step 5: Separate the $S$ best solutions into two groups ( $E$, $S-E$ ), and determine the size of neighborhood for each best solution. Note that neighborhood sizes are equal to $N E$ for solution group $E$ and $N O$ for solution group $(S-E)$.

Step 6: Generate solutions around the selected solutions within the neighborhood sizes $(N E, N O)$ and evaluate the fitness value from each patch. 


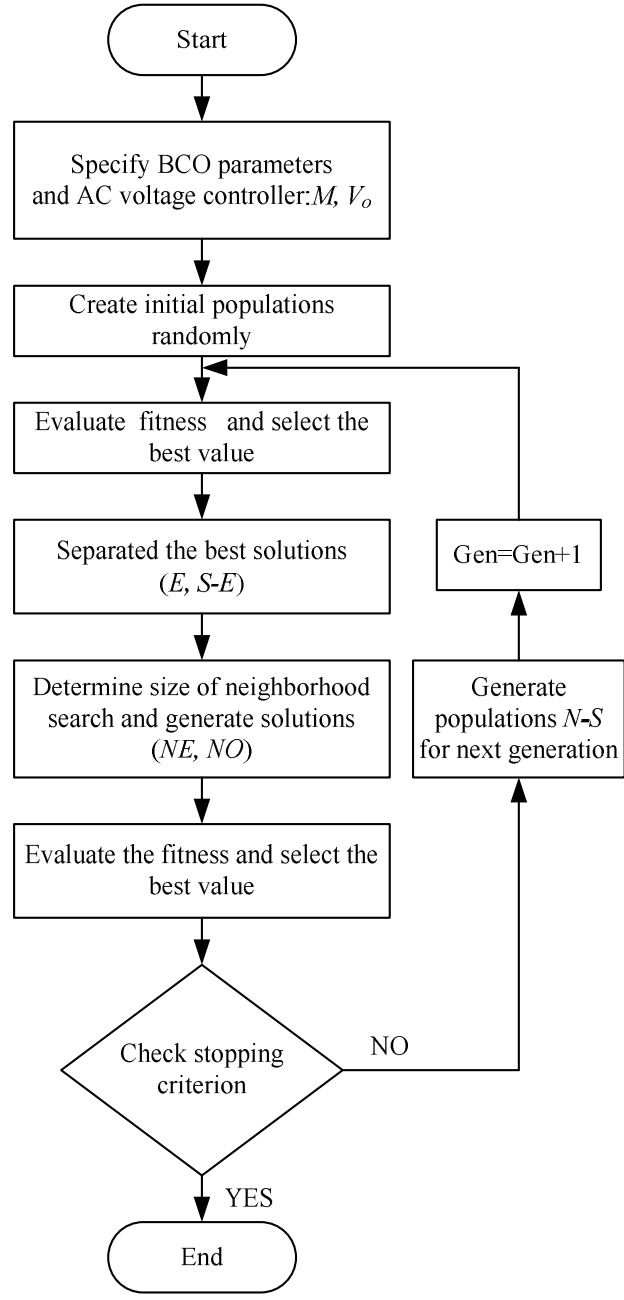

Fig. 2. Proposed BCO algorithm.

TABLE I

PARAMETER OF BCO

\begin{tabular}{|l|c|}
\hline \multicolumn{1}{|c|}{ Parameters } & Number \\
\hline Population size $(N)$ & 20 \\
Number of selected sites $(S)$ & 14 \\
Number of best sites $(E)$ & 10 \\
Number of bees around best sites $(N E)$ & 20 \\
Number of bees around other sites $(N O)$ & 10 \\
\hline
\end{tabular}

Step 7: Select the best solution from each patch.

Step 8: Check the stopping criterion. If the algorithm is not stopped, increase the iteration.

Step 9: Assign the new population $(N-S)$ to generate new switching angles. Then, return to Step 3.

\section{Simulation Results}

The PWM AC-AC converter is designed and simulated using two different software packages. First, the proposed $\mathrm{BCO}$ algorithm is implemented in the MATLAB
TABLE II

Optimal Angles ObTained by Proposed Method at Various Desired OutPut Voltage

\begin{tabular}{|c|c|c|c|c|c|c|}
\hline \multirow{2}{*}{$\begin{array}{c}\text { Output } \\
\text { voltage } \\
(\mathrm{V})\end{array}$} & $\alpha_{1}$ & $\beta_{1}$ & $\alpha_{2}$ & $\beta_{2}$ & $\alpha_{3}$ & $\beta_{3}$ \\
\cline { 2 - 7 } & 24.039 & 26.501 & 53.718 & 57.212 & 88.729 & 90 \\
\hline 30 & 25.606 & 27.823 & 55.119 & 59.330 & 87.288 & 90 \\
\hline 40 & 23.518 & 28.209 & 53.901 & 59.559 & 86.662 & 90 \\
\hline 50 & 20.249 & 29.637 & 53.128 & 59.866 & 86.130 & 90 \\
\hline 60 & 22.044 & 28.777 & 51.237 & 59.498 & 84.545 & 90 \\
\hline 70 & 19.715 & 29.800 & 49.147 & 59.673 & 84.400 & 90 \\
\hline 80 & 20.012 & 28.686 & 48.132 & 59.837 & 82.727 & 90 \\
\hline 90 & 20.170 & 29.625 & 43.740 & 58.569 & 82.210 & 90 \\
\hline 100 & 20.325 & 29.546 & 44.354 & 59.313 & 80.333 & 90 \\
\hline 110 & 18.421 & 29.254 & 42.850 & 59.264 & 79.066 & 90 \\
\hline 120 & 14.642 & 29.414 & 41.394 & 58.995 & 77.769 & 90 \\
\hline 130 & 10.415 & 28.033 & 39.619 & 58.620 & 75.989 & 90 \\
\hline 140 & 16.388 & 28.272 & 37.522 & 59.796 & 75.310 & 90 \\
\hline 150 & 17.052 & 25.581 & 36.265 & 59.891 & 73.011 & 90 \\
\hline 160 & 15.640 & 28.424 & 36.977 & 59.252 & 70.715 & 90 \\
\hline 170 & 9.351 & 26.697 & 34.079 & 59.422 & 69.571 & 90 \\
\hline 180 & 9.718 & 29.763 & 34.686 & 59.244 & 67.618 & 90 \\
\hline 190 & 5.903 & 25.753 & 31.947 & 58.648 & 64.681 & 90 \\
\hline 200 & 4.267 & 29.064 & 30.445 & 59.991 & 64.762 & 90 \\
\hline & & & & & & \\
\hline
\end{tabular}

environment to provide the optimal switching angles for the converter. Second, the designed PWM chopper is simulated by PSpice software with system parameters of $V_{i}=220 \mathrm{~V}, f=$ $50 \mathrm{~Hz}, R_{o}=240 \Omega, L_{o}=300 \mathrm{mH}$ and $M=3$ pulses. For the $\mathrm{BCO}$ algorithm, the required parameters are listed in table I. The BCO parameters are selected from an empirical examination with a reasonable cost of computation. This affects both the convergence characteristic and computational efficiency.

\section{A. Optimal Switching Angle Solution}

The optimal switching angles, obtained by the proposed $\mathrm{BCO}$ algorithm at various output voltage levels, are shown in table II.

\section{B. Convergence Characteristic}

Based on multiple runs of the simulation, BCO can provide optimal solutions with very little variation. The selected convergence solutions are shown in Figures 3 and 4. The solutions converge within 5 iterations. The minimum $T H D_{v}$ is 0.1574 . The mean and standard deviations of the solutions are 0.1616 and 0.0139 , respectively.

\section{Comparative Results}

The performance of the designed converter is investigated with different optimization techniques. Both the input and output parameters of the converter such as the current and 


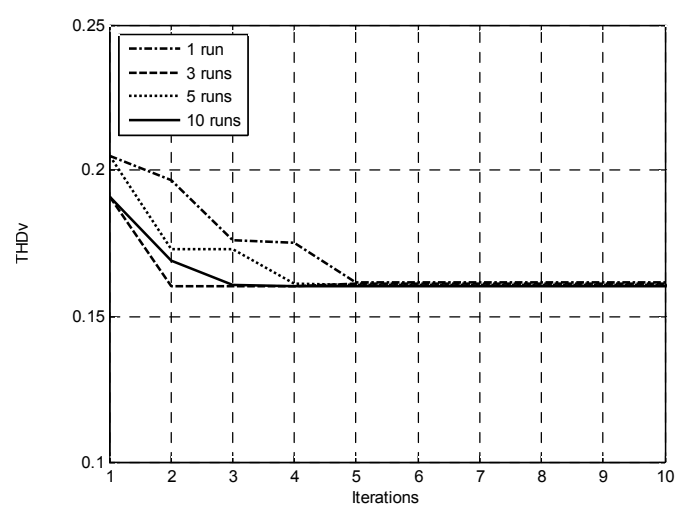

Fig. 3. Solution convergence from the proposed BCO approach.

TABLE III

Performance of the GA, PSO, and BCO At Output Voltage $=160 \mathrm{~V}$

\begin{tabular}{|c|c|c|c|c|c|}
\hline \multirow{2}{*}{ Method } & \multicolumn{2}{|c|}{ Output } & \multicolumn{3}{c|}{ Input } \\
\cline { 2 - 6 } & $T H D_{v}$ & $T H D_{i}$ & $T H D_{i}$ & $D P F$ & $P F_{i}$ \\
\hline BCO & 0.1615 & 0.1615 & 0.6421 & 0.9681 & 0.8146 \\
\hline $\begin{array}{c}\text { GA } \\
{[13]}\end{array}$ & 0.2079 & 0.2079 & 0.9436 & 0.9703 & 0.7057 \\
\hline $\begin{array}{c}\text { PSO } \\
{[16]}\end{array}$ & 0.2045 & 0.2045 & 0.9367 & 0.9723 & 0.7123 \\
\hline
\end{tabular}

voltage THD, and the power factors are shown. In the test, the output voltage of the converter is $160 \mathrm{~V}$. Test results from the proposed BCO, PSO and GA algorithms are compared in table III. The results indicate that $\mathrm{BCO}$ can provide a better solution than the other approaches in reducing voltage and current harmonics and improving the input power factor. It should be noted that the displacement power factor (DPF) is a power factor without considering harmonic distortions.

Fig. 4 shows the performance of the proposed BCO PWM technique when compared to GA and PSO results. Figure 4(a) shows the $T H D_{v}$ versus the output voltage. The results show that the $T H D_{v}$ of the proposed BCO PWM technique is lower than the results from the other techniques. And Figure 4(b) compares the results of the $T H D_{i}$ from both techniques. The simulation results indicate that the $T H D_{i}$ from the proposed BCO PWM technique is lower than the results from the other PWM techniques. In Figure 4(c), a profile of $P F_{i}$ against the output voltage is shown. It indicates that the proposed BCO PWM technique can effectively enhance the input power factor of the power source.

\section{EXPERIMENTAL RESULTS}

Here, an experiment on the PWM AC chopper is used to confirm the performance of the proposed technique. The system parameters used in the experiment are similar to the ones used in the simulation. The implemented laboratory prototype is shown in Figure 5.

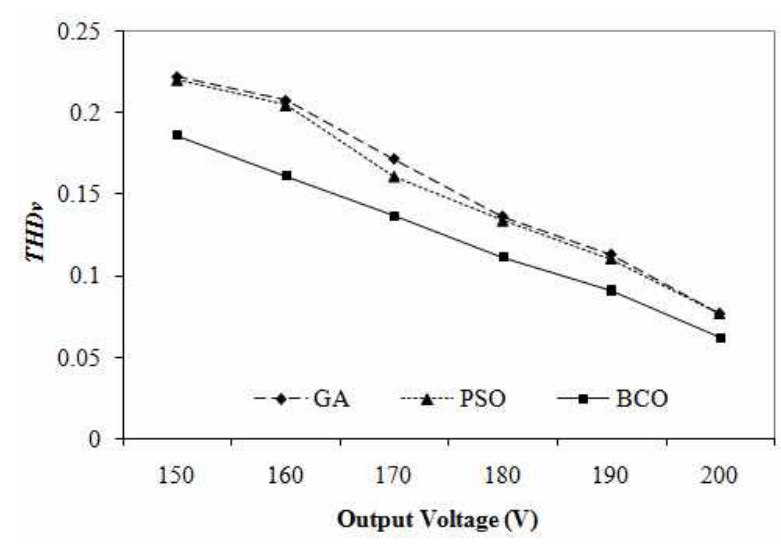

(a)

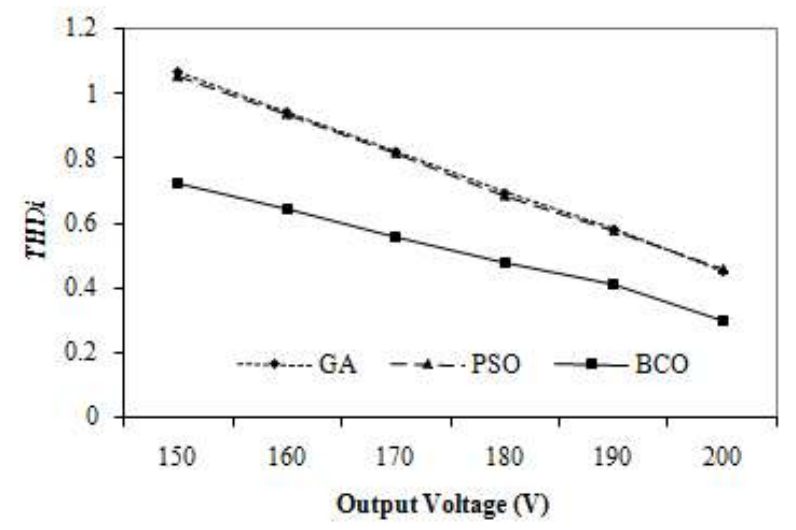

(b)

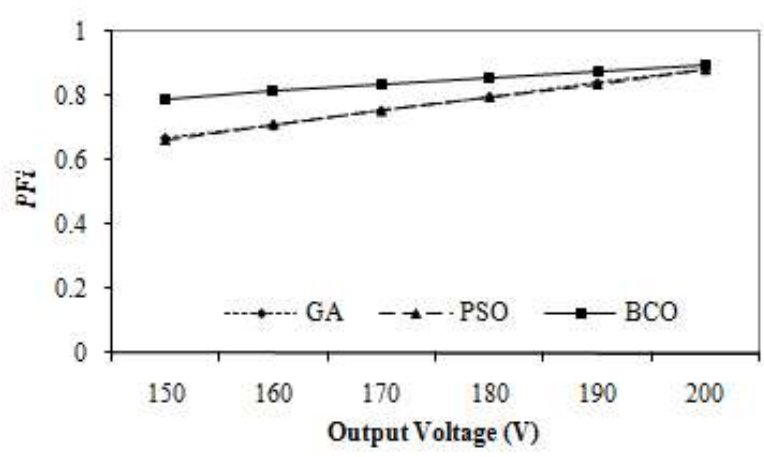

(c)

Fig. 4. Converter parameters versus output voltage using GA [13], PSO [16] and proposed BCO PWM. (a) Output voltage THD, (b) input current $T H D$. (c) Input power factor.

A PIC 16F628A microprocessor is adopted to generate the PWM for controlling the gate signals of the switching devices. The converter can vary the output voltage in the range of $20-220 \mathrm{~V}$. Here, the output voltage is set at $140 \mathrm{Vrms}$ to make a comparison between simulation and experimental results. The input and output waveforms are shown in Fig. 6 and 7 , respectively. The results indicate a significant correlation between the simulation and the experiment. In addition, Fig. 8 shows the experimental harmonic spectra of 


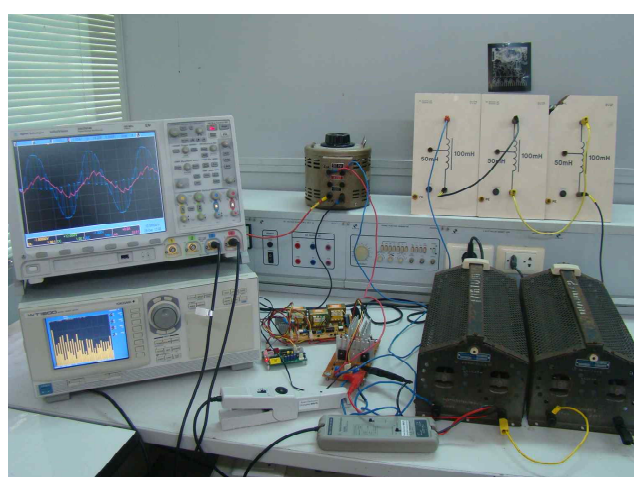

Fig. 5. Experimental equipment.

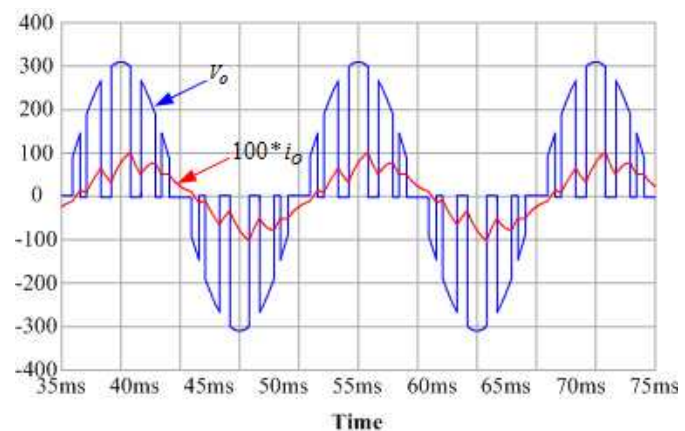

(a)

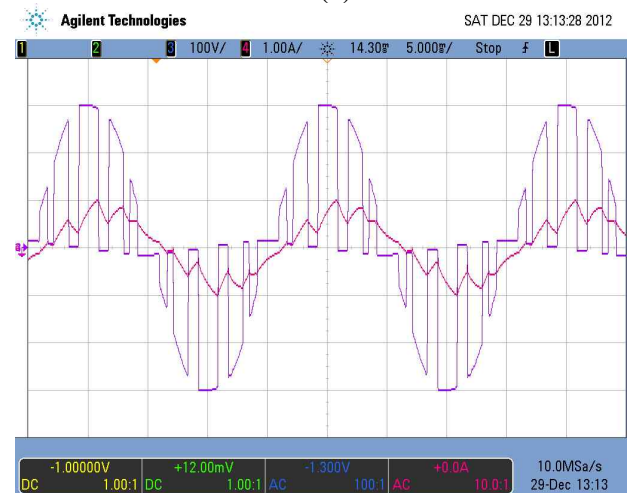

(b)

Fig. 6. Waveforms of output current and voltage. (a) Simulation results. (b) Experimental results (voltage, $100 \mathrm{~V} /$ div, current, 1 A/div.)

the output voltage when compared to the simulation. From the expanded harmonic spectra, the low frequency harmonics are a lot less. Thus, eliminating higher frequency harmonics can be done effectively using a regular low pass filter.

\section{CONCLUSIONS}

This paper proposes a harmonic reduction technique based on BCO for single phase PWM AC-AC converters. The optimal PWM switching angles are obtained by the proposed $\mathrm{BCO}$ algorithm. From the test results, $\mathrm{BCO}$ can provide a

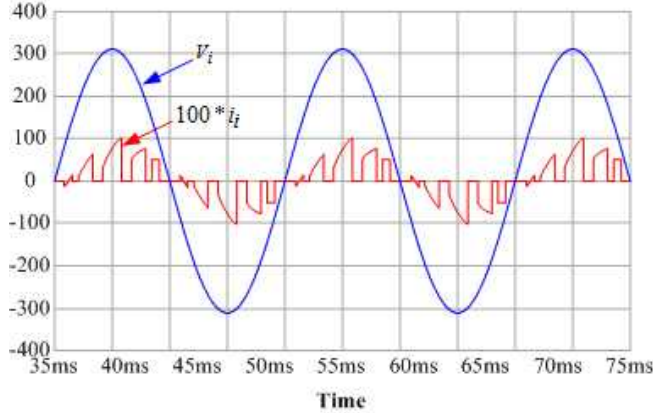

(a)

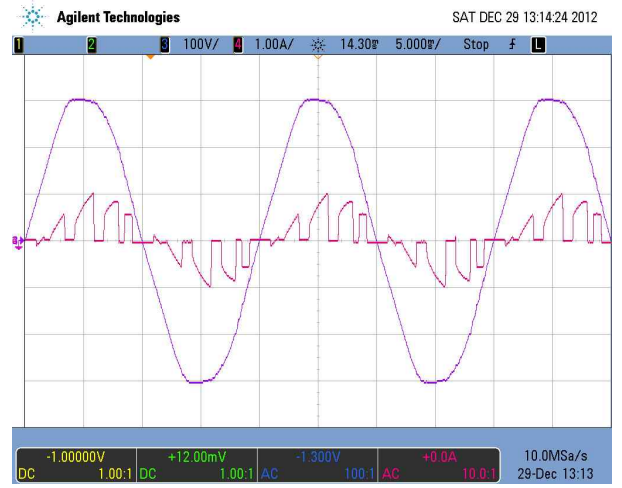

(b)

Fig. 7. Waveforms of input current and voltage. (a) simulation results and (b) experimental results (voltage, $100 \mathrm{~V} /$ div, current, 1 A/div).

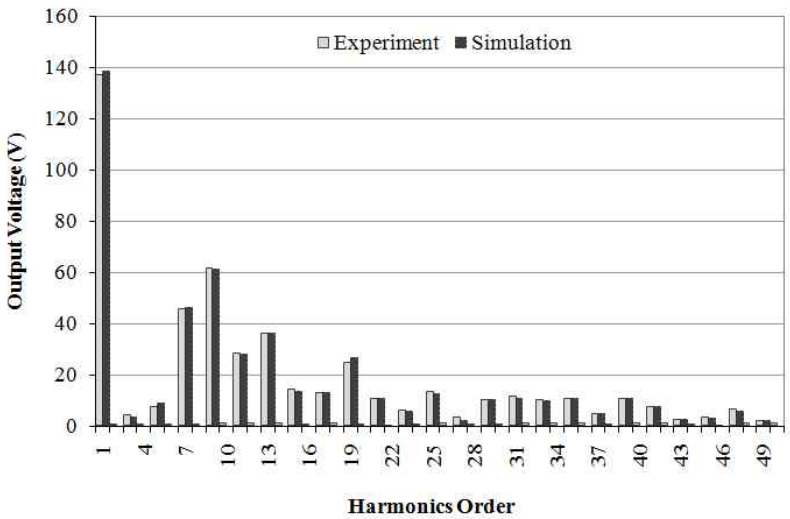

Fig. 8. Spectra of output voltage compared between experiment and simulation results.

better solution than GA and PSO in minimizing total harmonic distortions. In addition, the simulation and experimental results are correlated to confirm the performance in terms of improving power the quality and power factor. The proposed approach can be applied to design optimal switching patterns for other power converter topologies.

\section{REFERENCES}

[1] M. H. Rashid, Power Electronics Handbook, Academic Press, chap. 16, 2001. 
[2] M. E. Balci and M. H. Hocaoglu, "Effects of source voltage harmonic distortion on power factor compensation in triac controlled AC chopper circuits," in Proc. PEDS, pp. 1199-1204, Nov. 2005.

[3] H. S. Patel and R. G. Hoft, "Generalized techniques of harmonic elimination and voltage control in thyristor inverters: part I-harmonic elimination," IEEE Trans. Ind. Appl., Vol. IA-9, No. 3, pp. 310-317, May. 1973.

[4] H. R.Mohammadi, S. Falahati and M. Zeraati, "A new method for selective harmonic elimination in voltage source inverter using imperialist competitive algorithm," in Proc. PSTC, pp. 175-180, Feb. 2012.

[5] S. Debnath and R. N. Ray, "Harmonic elimination in multilevel inverter using GA and PSO: A comparison," in Proc. SCEECS, pp. 1-5, Mar. 2012.

[6] W. Fei, B. Wu, and Y. Huang, "Half-wave symmetry selective harmonic elimination method for multilevel voltage source inverters," IET Power Electron., Vol. 4, No. 3, pp. 342-351, Mar. 2011.

[7] Z. Salam, "An on-line harmonic elimination pulse width modulation scheme for voltage source inverter," Journal of Power Electronics, Vol. 10, No. 1, pp. 43-50, Jan. 2010.

[8] R. Salehi, N. Farokhnia, M. Abedi, and S. H. Fathi, "Elimination of low order harmonics in multilevel inverters using genetic algorithm, Journal of Power Electronics, Vol. 11, No. 2, pp. 132-139, Mar. 2011.

[9] K. Sundareswaran and A. P. Kumar, "Voltage harmonic elimination in PWM A.C. chopper using genetic algorithm," in Proc. IEE Electr. Power Appl., Vol. 151, No. 1, pp. 26-31, 2004.

[10] S. S. Rao and S. N. Warangal, "Improving voltage regulation and harmonic elimination using genetic algorithm in PWM choppers," in Proc. INTELEC, pp. 449-454, Sep. 2005.

[11] A. K. Al-Othman, N. A. Ahmed, A. M. Al-Kandari, and H. K. Ebraheem, "Selective harmonic elimination of PWM AC/AC voltage controller using hybrid RGA-PS approach," in Proc. World Academy of Science, Engineering and Technology 29, pp. 140-146, 2007.

[12] M. S. A. Dahidah and M. V. C. Rao, "A hybrid genetic algorithm for selective harmonic elimination PWM AC/AC converter control," Electric Engineering, Vol. 89, No. 4, pp. 285-291, Mar. 2007.

[13] S. Kaitwanidvilai and P. Piyarungsan, "Low-cost microprocessor-based alternating current voltage controller using genetic algorithms and neural network," IET Power Electron., Vol. 3, No. 4, pp. 490-499, Jul. 2010.

[14] P. Jitta, S. Kaitwanidvilai, and A. Ngaopitakkul, "Switching angle design for pulse width modulation AC voltage controller using genetic algorithm and distributed artificial neural network," in Proc. IMECS, pp. 970-974, 2011.

[15] A. Kouzou, S. Saadi, M.O. Mahmoudi, and M. S. Boucherit, "Voltage quality enhancement of PWM AC voltage controller using particle swarm optimization," in Proc. POWERENG, pp. 309-314, 2009.

[16] P. Piyarungsan and S. Kaitwanidvilai, "Harmonic reduction technique in PWM AC voltage controller using particle swarm optimization and artificial neural network," in Proc. IMECS, pp. 1327-1332, 2010.

[17] M. Z. Bilgin and U. Kilicarslan, "Voltage harmonic elimination of PWM AC chopper using artificial neural network," in Proc. ELECO, pp. 173-178, 2010.

[18] S. M. Sadr, M. Monfared, and H. R. Mashhadi, "Application of PSO for Selective Harmonic Elimination in a PWM AC/AC Voltage Regulator," in Proc. ICCKE, pp.
62-65, 2012.

[19] J. Bindu, S. Muralidharan, S. Selvaperumal, and M. Muhaidheen, "Genetic algorithm based selective harmonic elimination in PWM AC-AC converter," in Proc. ICONRAEeCE, pp. 393-397, 2011.

[20] D. Karaboga, "An Idea Based on Honey Bee Swarm for Numerical Optimization," Technical Report TR06, Faculty of Engineering, Erciyes University, Turkey, 2005.

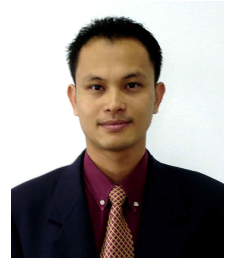

Wanchai Khamsen was born in Lampang Province, Thailand, in 1974. He received his B.S. degree in Technical Education from the Rajamamgla Institute of Technology, Thailand, in 1997, his M.Eng. degree in Electrical Engineering from King Mongkut's Institute of Technology North Bangkok, Bangkok, Thailand, in 2003, and his Ph.D. degree from Mahasarakham University, Maha Sarakham, Thailand, in 2013. $\mathrm{He}$ is currently working as an Assistant Professor for the Faculty of Engineering, Rajamamgla University of Technology Lanna, Lampang, Thailand. His current research interests include ac choppers, converter systems for improving power quality, power factor and optimization techniques.

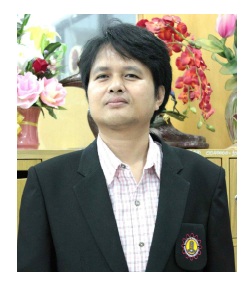

Apinan Aurasopon was born in Amnat Charoen Province, Thailand, in 1971. He received his B.Eng. degree in Electronic Engineering from Northeastern College, Khon Kaen, Thailand, in 1995, his M.Eng. and $\mathrm{Ph} . \mathrm{D}$. degrees in Electrical Engineering from King Mongkut's University of Technology Thonburi, Bangkok, Thailand, in 2003 and 2007, respectively. He was a Lecturer in the Department of Electrical Engineering, Faculty of Engineering, Burapha University (BU), Chonburi, Thailand, in 2007. He was transferred to the Faculty of Engineering, Mahasarakham University (MSU), Maha Sarakham, Thailand, in 2008, where he is currently an Assistant Professor. His current research interests include soft-switched converters, ac choppers, converter systems for improving power quality, and the application of electronics and computer to agriculture.

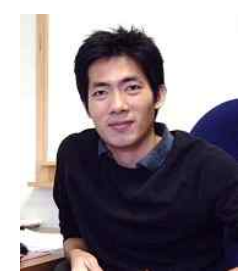

Chanwit Boonchuay received his D.Eng. degree in Electric Power System Management from the Asian Institute of Technology (AIT), Khlong Luang, Thailand, in 2011. He was a Visiting Scholar at the Center for Electrical Energy System (CEES), of Hong Kong, Hong Kong, China, and the Department of Electrical Engineering and Computer Science, University of Tennessee, Knoxville, TN, USA, in 2009 and 2010, respectively. He is currently the Head of the Center for Electrical and Embedded System Technology (CEEST), Rajamangala University of Technology Rattanakosin, Prachuap Khiri Khan, Thailand. His current research interests include artificial intelligence applications, power system optimization, power system restructuring and deregulation, risk management in energy markets, distributed generation, and smart grids. 